Article

\title{
The Influence of Thermal Residual Stresses on Mechanical Properties of Silicon Nitride-Based Composites
}

\author{
Aleksandra Dubiel *(D), Grzegorz Grabowski®, Marcin Goły@ and Stanisław Skrzypek \\ AGH University of Science and Technology, al. Mickiewicza 30, 30-059 Krakow, Poland; \\ grzegorz.grabowski@agh.edu.pl (G.G.); marcing@agh.edu.pl (M.G.); skrzypek@agh.edu.pl (S.S.) \\ * Correspondence: adubiel@agh.edu.pl
}

Received: 27 December 2019; Accepted: 27 February 2020; Published: 1 March 2020

check for updates

\begin{abstract}
In this work, two kinds of silicon nitride-based composites, namely, those with titanium nitride or silicon carbide additives, were sintered using the hot pressing technique (HP). The phase composition, microstructure, and mechanical and elastic properties of the materials were characterized. Three-dimensional geometric models of the composites were created on the basis of microstructure parameters. Using these models, bulk residual thermal stresses were calculated by the finite element method (FEM). Surface stresses were determined using the XRD method of $\sin ^{2} \psi$.
\end{abstract}

Keywords: ceramic-ceramic composites; residual thermal stresses; $\sin ^{2} \psi$; FEM modeling; silicon nitride

\section{Introduction}

Silicon nitride-based composites are widely used structural materials. Their commercial usage is due to their great mechanical properties (high stiffness, strength, and toughness), high thermal and chemical resistance, and outstanding shock resistance [1,2]. The two most commonly used secondary phases in silicon nitride-based composites are titanium nitride and silicon carbide. Both are reported to influence the mechanical properties of composites. In $\mathrm{Si}_{3} \mathrm{~N}_{4}-\mathrm{TiN}$ composites, an increase in fracture toughness is usually observed, but the strength of the materials may decrease [3]. There are also some works $[4,5]$ where an increase in the strength and fracture toughness is reported. In the case of $\mathrm{Si}_{3} \mathrm{~N}_{4}-\mathrm{SiC}$, increased strength was observed by adding nanoparticles [6,7]. Nanoparticles located in the grain boundary phase are also reported to increase the toughness of the materials by strengthening the weak amorphous phase [8].

Due to the low self-diffusion rate and very strong covalent bonding, additives are often used when sintering silicon nitride $[9,10]$. A mixture of aluminum oxide and yttrium oxide is the most popular and effective additive. Together, they form an amorphous phase surrounding elongated silicon nitride grains. This phase strongly influences the properties of the materials [11-14].

When a two-phase material is sintered at high temperatures and then cooled down to room temperature, residual thermal stress may occur. The reason for such stress is the difference between the thermal expansion and elastic properties of the phases [15]. This stress affects the mechanical properties of ceramic-ceramic materials, especially fracture toughness. In silicon nitride, residual stresses have been reported to appear as a result of the mismatched thermal expansion coefficient $(\alpha)$ of $\beta-\mathrm{Si}_{3} \mathrm{~N}_{4}$ grains and the grain boundary glassy phase, which were calculated using analytical methods by Peterson and Tien [16] and the finite element method (FEM) by Wippler and Bohlke [17]. According to their findings, residual stresses are the factors that most greatly influence the fracture toughness of polycrystalline silicon nitride. In silicon nitride-based composites, there are at least three 
phases with different thermal expansion coefficients in one material. This suggests that the influence of residual stresses on mechanical properties may by significant. In a study on the residual stresses in silicon nitride-based composites, Bao, Liu, and Huang [18] investigated the influence of different grain sizes, shapes, thermal expansion coefficients, and applied loads on the failure of silicon nitride-based materials. However, they did not imitate the real microstructure of silicon nitride for these simulations and they completely neglected the grain boundary glassy phase. Residual thermal stresses appear to be one of the most important factors influencing the mechanical properties of silicon nitride-based composites. Despite that, to the best of our knowledge, there are no reports of complex simulations of stresses, considering all phases in silicon nitride-based composites that have been compared with experimental mechanical testing.

In this study, two kinds of silicon nitride-based composites $\left(\mathrm{Si}_{3} \mathrm{~N}_{4}-\mathrm{SiC}\right.$ and $\left.\mathrm{Si}_{3} \mathrm{~N}_{4}-\mathrm{TiN}\right)$ were investigated. The secondary phases were chosen in such a way that, in one composite, the thermal expansion coefficient of the matrix was much smaller than the dispersed phase $\left(\alpha_{\mathrm{Si} 3 \mathrm{~N} 4} \approx 3.5 \times 10^{-6} \mathrm{~K}^{-1}\right.$, $\left.\alpha_{\mathrm{TiN}}=9.4 \times 10^{-6} \mathrm{~K}^{-1}\right)$, and in the other, the coefficient values were similar $\left(\alpha_{\mathrm{SiC}} \approx 4.4 \times 10^{-6} \mathrm{~K}^{-1}\right)$. Residual thermal stresses in the bulk of the materials were simulated for $3 \mathrm{D}$ microstructures of polycrystalline silicon nitride (reference sample) and composites containing $20 \mathrm{vol} \%$ of the dispersed phase. These geometric models were created based on SEM observations of real materials, considering two phases for the reference sample and all three phases present in the composites. To complete the information about stresses in composites, surface residual stresses were determined using XRD. Moreover, this complex information about stresses in materials was connected with an investigation of the microstructure and mechanical properties of silicon nitride-based composites. This research provides information about the influence of residual stresses on the mechanical properties of silicon nitride-based composites.

\section{Materials and Methods}

\subsection{Preparation of Materials}

Polycrystalline silicon nitride and composites with varying amounts of titanium nitride or silicon carbide, with $6 \mathrm{wt} \%$ aluminum oxide and $4 \mathrm{wt} \%$ yttrium oxide as sintering additives, were prepared from the following commercially available powders: $\alpha-\mathrm{Si}_{3} \mathrm{~N}_{4}$ grade M-11 higher purity (H.C. Stark, Munich, Germany), $\mathrm{Y}_{2} \mathrm{O}_{3}$ grade $\mathrm{C}$ (H.C. Stark), $\mathrm{Al}_{2} \mathrm{O}_{3}$ Taimicron TM-DAR (Tamei CHEMICALS), TiN grade A (H.C. Stark), and SiC UF-15 (H.C. Stark). The compositions of the prepared materials are listed in Table 1. Materials were sintered using the hot pressing (HP) technique at $1750{ }^{\circ} \mathrm{C}$ under $25 \mathrm{MPa}$ pressure in nitrogen flow. Discs obtained after sintering $(5 \mathrm{~cm}$ diameter) were cut as samples for further measurements.

Table 1. Composition of prepared materials.

\begin{tabular}{ccc}
\hline Material & $\begin{array}{c}\mathbf{S i}_{3} \mathbf{N}_{\mathbf{4}} \text { matrix [vol \%] } \\
\text { 90 wt } \% \mathbf{S i}_{3} \mathbf{N}_{\mathbf{4}}, \mathbf{6} \mathbf{~ w t} \% \mathbf{A l}_{\mathbf{2}} \mathbf{O}_{3}, \mathbf{4} \mathbf{w t} \% \mathbf{Y}_{\mathbf{2}} \mathbf{O}_{3}\end{array}$ & $\begin{array}{c}\text { Secondary phas [vol \%] } \\
\text { (TiN/SiC) }\end{array}$ \\
\hline $\mathrm{Si}_{3} \mathrm{~N}_{4}$ & $100 \mathrm{vol} \%$ & - \\
\hline $\mathrm{Si}_{3} \mathrm{~N}_{4}+5 \% \mathrm{TiN}$ & $95 \mathrm{vol} \%$ & $5 \mathrm{vol} \%$ \\
\hline $\mathrm{Si}_{3} \mathrm{~N}_{4}+10 \% \mathrm{TiN}$ & $90 \mathrm{vol} \%$ & $10 \mathrm{vol} \%$ \\
\hline $\mathrm{Si}_{3} \mathrm{~N}_{4}+15 \% \mathrm{TiN}$ & $85 \mathrm{vol} \%$ & $15 \mathrm{vol} \%$ \\
\hline $\mathrm{Si}_{3} \mathrm{~N}_{4}+20 \% \mathrm{TiN}$ & $80 \mathrm{vol} \%$ & $20 \mathrm{vol} \%$ \\
\hline $\mathrm{Si}_{3} \mathrm{~N}_{4}+5 \% \mathrm{SiC}$ & $95 \mathrm{vol} \%$ & $5 \mathrm{vol} \%$ \\
\hline $\mathrm{Si}_{3} \mathrm{~N}_{4}+10 \% \mathrm{SiC}$ & $90 \mathrm{vol} \%$ & $10 \mathrm{vol} \%$ \\
\hline $\mathrm{Si}_{3} \mathrm{~N}_{4}+15 \% \mathrm{SiC}$ & $85 \mathrm{vol} \%$ & $15 \mathrm{vol} \%$ \\
\hline $\mathrm{Si}_{3} \mathrm{~N}_{4}+20 \% \mathrm{SiC}$ & $80 \mathrm{vol} \%$ & $20 \mathrm{vol} \%$ \\
\hline
\end{tabular}




\subsection{Materials Characterization}

The density of the specimens was measured by Archimedes's method using distilled water as the immersing medium according to ASTM C373-88. XRD measurements were taken using the PANalytical Empyrean (Malvern Panalytical, Malvern, UK) diffractometer with copper radiation $\left(\lambda_{\mathrm{Cu}}=1.5406 \AA\right.$ ). SEM (Nova NanoSEM 200 FEI, FEI, Tokyo, Japan) with EDS analysis was used for microstructure observation. The Young's modulus of the materials was determined by the ultrasonic wave transition method using an ultrasonic flaw detector (Panametrics Epoch III, Olympus, Waltham, MA, USA). The hardness was determined by the Vickers indentation method using a Future FV-700 hardness tester, applying a load of $4.905 \mathrm{~N}$. Fracture toughness was measured using the single-edge notched beam method (SENB), and the flexural strength was measured using a three-point bending test. The distance between supports in each measurement was $20 \mathrm{~mm}$.

\subsection{Geometric 3D Models of Microstructure}

Geometric models of the reference sample and composites containing $20 \mathrm{vol} \% \mathrm{of} \mathrm{SiC} \mathrm{or} \mathrm{TiN} \mathrm{were}$ prepared based on SEM observations of microstructures. The following constituents were considered when creating the 3D models: elongated grains of silicon nitride with sizes between 0.8 and $4.9 \mu \mathrm{m}$ and an aspect ratio (length to width) of 4 , the amorphous oxide phase (consisting of $\mathrm{Al}_{2} \mathrm{O}_{3}$ and $\mathrm{Y}_{2} \mathrm{O}_{3}$ ) surrounding $\mathrm{Si}_{3} \mathrm{~N}_{4}$ grains with a thickness of $0.03 \mu \mathrm{m}$, and the isotropic $\mathrm{Si}_{3} \mathrm{~N}_{4}$, which refers to very small $\mathrm{Si}_{3} \mathrm{~N}_{4}$ grains with a width below $0.2 \mu \mathrm{m}$. Additionally, in the composites, isometric grains (icosahedron) of the secondary phase, with sizes between 0.5 and $1.2 \mu \mathrm{m}$, were added. The external dimensions of the geometric model (RVE) were $5 \times 5 \times 5 \mu \mathrm{m}$. It was also assumed that grains cannot penetrate into each other.

\subsection{Materials Data for Modeling of Residual Stresses}

The elastic properties of elongated hexagonal $\beta-\mathrm{Si}_{3} \mathrm{~N}_{4}$ grains and hexagonal $\mathrm{SiC}$ are described by six elastic constants $\left(C_{i j}\right)$, while the elastic properties of regular TiN are described by three elastic constants $\left(C_{i j}\right)$, The literature values of all $C_{i j}$ used for modeling are listed in Table 2. For the description of thermal expansion of silicon nitride, silicon carbide, and titanium nitride in two crystallographic directions ( $\mathrm{a}$ and $\mathrm{c}$ ), average thermal expansion coefficients determined in the temperature range of $25-1000{ }^{\circ} \mathrm{C}$ were used. Data are presented in Table 2.

Table 2. Elastic constant $C_{\mathrm{ij}}$ and thermal expansion coefficients.

\begin{tabular}{|c|c|c|c|c|c|c|c|c|c|}
\hline Phase & & $\begin{array}{c}\mathrm{C} 11 \\
\text { (GPa) }\end{array}$ & $\begin{array}{c}\mathrm{C} 12 \\
\text { (GPa) }\end{array}$ & $\begin{array}{c}\mathrm{C} 13 \\
(\mathrm{GPa})\end{array}$ & $\begin{array}{c}\text { C33 } \\
\text { (GPa) }\end{array}$ & $\begin{array}{c}\mathrm{C} 44 \\
\text { (GPa) }\end{array}$ & $\begin{array}{c}\text { C66 } \\
\text { (GPa) }\end{array}$ & $\begin{array}{c}\alpha_{a} \\
\left(K^{-1}\right)\end{array}$ & $\begin{array}{c}\alpha_{c} \\
\left(K^{-1}\right)\end{array}$ \\
\hline$\beta-\mathrm{Si}_{3} \mathrm{~N}_{4}$ & {$[19,20]$} & 433 & 195 & 127 & 574 & 108 & 119 & $3.23 \times 10^{-6}$ & $3.72 \times 10^{-6}$ \\
\hline $\mathrm{SiC}$ & {$[21,22]$} & 478 & 98 & 56 & 522 & 148 & 191 & $4.51 \times 10^{-6}$ & $4.19 \times 10^{-6}$ \\
\hline $\mathrm{TiN}$ & {$[23,24]$} & 625 & 165 & - & - & 163 & - & $9.35 \times 10^{-6}$ & $9.35 \times 10^{-6}$ \\
\hline
\end{tabular}

The amorphous oxide phase formed by sintering additives, with isotropic properties, is described by Young's modulus, the thermal expansion coefficient, and Poisson's ratio, which are presented in Table 3. To prepare the 3D model, it was assumed that small grains of $\mathrm{Si}_{3} \mathrm{~N}_{4}$, which are mostly isometric, also have isotropic properties. Values of Young's modulus, Poisson's ratio, and thermal expansion for the isotropic $\mathrm{Si}_{3} \mathrm{~N}_{4}$ were calculated as the Hill's average [25] based on the elastic constant (Table 2) and are presented in Table 3.

Table 3. Properties of isotropic phases.

\begin{tabular}{cccc}
\hline Phase & $\mathbf{E}(\mathbf{G P a})$ & $\boldsymbol{v}$ & $\boldsymbol{\alpha}_{\text {iso }}\left(\mathbf{1 0}^{-\mathbf{6}} \mathbf{K}^{-\mathbf{1}}\right)$ \\
\hline Isotropic $\mathrm{Si}_{3} \mathrm{~N}_{4}$ & 416 & 0.37 & 3.39 \\
Amorphous oxide phase [26] & 133 & 0.29 & 5.67 \\
\hline
\end{tabular}




\subsection{Determination of Residual Stresses Using FEM}

The loads of the model were cooled from 1000 to $25^{\circ} \mathrm{C}$. The upper temperature was the temperature in which our system was stiff and created stresses that could not be relaxed. In this study, the upper temperature was selected based on dilatometric measurements of samples (Figure 1).

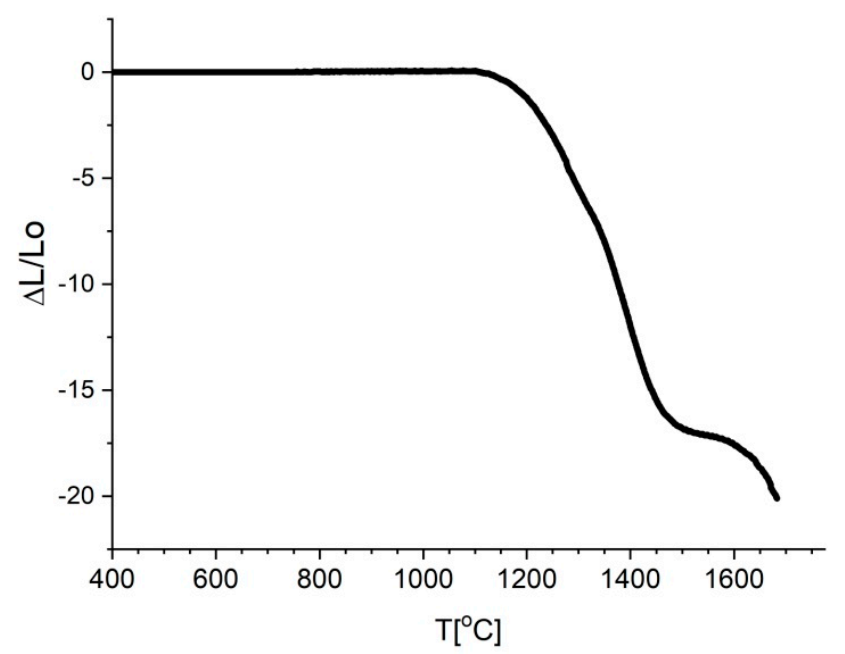

Figure 1. Dilatometric measurements of $\mathrm{Si}_{3} \mathrm{~N}_{4}+6 \% \mathrm{Al}_{2} \mathrm{O}_{3}+4 \% \mathrm{Y}_{2} \mathrm{O}_{3}$.

The shrinkage started around $1100{ }^{\circ} \mathrm{C}$. The temperature considered in modeling was $1000{ }^{\circ} \mathrm{C}$ due to pressure applied during the HP process. When the pressure was applied, diffusion started at lower temperatures.

Because the geometric models were periodic, periodic boundary conditions (PBCs) were used in finite element analyses. PBCs require joining displacements of corresponding nodes (being on opposite, periodic faces of the model) $[27,28]$. The implementation of PBCs was based on dummy nodes that matched the displacement of the corresponding model walls. The procedure used was described in detail by Grabowski [29]. The number of independent realizations, with the assumed RVE sizes, was calculated based on the differences between the mean strains recorded for perpendicular directions of the model. These differences, which were connected with the anisotropy of the material, allowed us to determine the dispersion, on the basis of which the number of necessary independent realizations was estimated to obtain results with a maximum permissible error of $1 \%$ and a confidence level of 0.95 [29]. For $\mathrm{Si}_{3} \mathrm{~N}_{4}$, the number of realizations was five; for composite materials, due to the replacement of elongated anisotropic $\mathrm{Si}_{3} \mathrm{~N}_{4}$ grains by isometric grains of the secondary phase, the number of realizations decreased. In the $\mathrm{Si}_{3} \mathrm{~N}_{4}-\mathrm{TiN}$ system, in which differences in thermal expansion between phases were the largest, it was three, and for $\mathrm{Si}_{3} \mathrm{~N}_{4}-\mathrm{SiC}$, the number was smaller. However, it was assumed for both composites that analyses would be made for three realizations.

\subsection{Measurement of Stresses Using the $\operatorname{Sin}^{2} \psi$ Method}

Before measurement of stresses by X-ray diffraction, samples were annealed to release stresses that were created during cutting and polishing [15]. To avoid grain growth during annealing, the applied temperature was below the Tammann temperature to only allow diffusion on grain boundaries. Samples were annealed for $2 \mathrm{~h}$ at $1200^{\circ} \mathrm{C}$.

The XRD measurements for stress analysis were taken using a Bruker D8 Advance diffractometer with the cobalt radiation wavelength $\left(\lambda_{C_{0}}=1.7902 \AA\right)$. The $\{321\}$ diffraction line was used for determination of residual stress in $\mathrm{Si}_{3} \mathrm{~N}_{4}$, line $\{400\}$ for $\mathrm{TiN}$, and $\{202\}$ for $\mathrm{SiC}$, and the tilt angle $\psi$ was in 
the range of $0^{\circ}-40^{\circ}$. The $\mathrm{X}$-ray diffraction methods for determining residual stresses were based on the literature and our own elaborations. The average lattice strain in the $L_{3}$ direction was equal to [30-32]

$$
\begin{aligned}
& <\varepsilon^{\prime}(\varphi, \psi)>_{(h k l)}=s_{1}(h k l)\left(\sigma_{11}^{I}+\sigma_{22}^{I}+\sigma_{33}^{I}\right)+\frac{1}{2} s_{2}(h k l)\left(\sigma_{11}^{I} \cos ^{2} \varphi+\sigma_{22}^{I} \sin ^{2} \varphi+\sigma_{12}^{I} \sin 2 \varphi\right) \sin ^{2} \psi \\
& +\frac{1}{2} s_{2}(h k l) \sigma_{33}^{I} \cos ^{2} \psi+\frac{1}{2} s_{2}(h k l)\left(\sigma_{13}^{I} \cos \varphi+\sigma_{23}^{I} \sin \varphi\right) \sin 2 \psi
\end{aligned}
$$

where $s_{1}(h k l)$ and $s_{2}(h k l)$ are diffraction elastic constants for quasi-isotropic polycrystalline, and $\sigma_{i j}^{I}$ macrostresses are defined with respect to the sample system. The general relation between the $\varepsilon^{\prime}(\varphi, \psi)$ and $\sigma^{\prime}{ }_{i j}$ components is usually expressed as

$$
\varepsilon_{\varphi, \psi}^{\prime}=F_{i j,(h k l) \varphi, \psi} \cdot \sigma_{i j}^{I}
$$

where $F_{i j}$ is the diffraction elastic constant for $\{\mathrm{hkl}\}$ reflection.

If the shear components of the stress tensor are neglected and the assumptions of the quasi-isotropic behavior of $F_{i j}$ are neglected, the simplification of the above equation for the plain stress field (assumed for the surface) can be expressed as

$$
\varepsilon \varepsilon_{i j}=s_{1}\left(\sigma^{\prime}{ }_{11}+\sigma_{22}^{\prime}\right)+\frac{1}{2} s_{2}\left(\sigma_{11}^{\prime} \cos ^{2} \varphi+\sigma_{22}^{\prime} \sin ^{2} \varphi+\sigma_{12}^{\prime} \sin 2 \varphi\right) \sin ^{2} \psi
$$

This simplified calculation was used to measure thermal-origin residual macrostresses in sintered samples.

\section{Results and Discussion}

\subsection{Materials Characterization}

The prepared materials had high densities (Table 4). XRD analysis confirmed the presence of the assumed phases in the materials: $\beta-\mathrm{Si}_{3} \mathrm{~N}_{4}$ in polycrystalline silicon nitride, and $\beta-\mathrm{Si}_{3} \mathrm{~N}_{4}$ and silicon carbide or titanium nitride in the composites (Figure 2a-c). Sintering additives formed the amorphous phase, which was not visible in XRD patterns.

Table 4. Density and elastic and mechanical properties of polycrystalline silicon nitride and prepared composites.

\begin{tabular}{cccccc}
\hline Material & Density & $\begin{array}{c}\mathbf{E} \\
\mathbf{( G P a )}\end{array}$ & $\begin{array}{c}\mathbf{K}_{\mathbf{I C}} \\
\left(\mathbf{M P a} \cdot \mathbf{m}^{\mathbf{0 . 5}} \mathbf{)}\right.\end{array}$ & $\begin{array}{c}\mathbf{\sigma} \\
\mathbf{( M P a})\end{array}$ & $\begin{array}{c}\text { HV } \\
(\mathbf{G P a})\end{array}$ \\
\hline $\mathrm{Si}_{3} \mathrm{~N}_{4}$ & $3.20 \pm 0.01$ & $298 \pm 4$ & $8.5 \pm 0.9$ & $756 \pm 96$ & $13.3 \pm 0.3$ \\
$\mathrm{Si}_{3} \mathrm{~N}_{4}+5 \% \mathrm{SiC}$ & $3.19 \pm 0.01$ & $302 \pm 5$ & $6.0 \pm 0.8$ & $964 \pm 138$ & $14.3 \pm 0.4$ \\
$\mathrm{Si}_{3} \mathrm{~N}_{4}+10 \% \mathrm{SiC}$ & $3.19 \pm 0.01$ & $301 \pm 5$ & $5.9 \pm 0.6$ & $884 \pm 203$ & $14.4 \pm 0.3$ \\
$\mathrm{Si}_{3} \mathrm{~N}_{4}+15 \% \mathrm{SiC}$ & $3.20 \pm 0.01$ & $313 \pm 5$ & $4.7 \pm 0.4$ & $884 \pm 177$ & $15.3 \pm 0.5$ \\
$\mathrm{Si}_{3} \mathrm{~N}_{4}+20 \% \mathrm{SiC}$ & $3.19 \pm 0.01$ & $317 \pm 5$ & $4.6 \pm 0.6$ & $898 \pm 192$ & $15.3 \pm 0.3$ \\
$\mathrm{Si}_{3} \mathrm{~N}_{4}+5 \% \mathrm{TiN}$ & $3.33 \pm 0.01$ & $298 \pm 4$ & $7.8 \pm 0.4$ & $700 \pm 49$ & $13.5 \pm 0.6$ \\
$\mathrm{Si}_{3} \mathrm{~N}_{4}+10 \% \mathrm{TiN}$ & $3.40 \pm 0.01$ & $309 \pm 4$ & $8.6 \pm 0.6$ & $776 \pm 46$ & $13.5 \pm 0.4$ \\
$\mathrm{Si}_{3} \mathrm{~N}_{4}+15 \% \mathrm{TiN}$ & $3.49 \pm 0.01$ & $314 \pm 4$ & $8.8 \pm 0.6$ & $803 \pm 36$ & $13.9 \pm 0.4$ \\
$\mathrm{Si}_{3} \mathrm{~N}_{4}+20 \% \mathrm{TiN}$ & $3.65 \pm 0.01$ & $322 \pm 12$ & $8.9 \pm 0.3$ & $820 \pm 49$ & $13.6 \pm 0.4$ \\
\hline
\end{tabular}

The SEM investigation revealed dense microstructures in all materials. Examples of images of the microstructure are shown in Figure 3. Elongated dark-grey silicon nitride grains with an aspect ratio of around 4 were surrounded by a thin layer of the white amorphous phase formed by sintering additives. There was also some amount of small isometric grains of silicon nitride visible in the microstructure. In $\mathrm{Si}_{3} \mathrm{~N}_{4}-$ TiN systems (Figure $3 \mathrm{~b}$ ), white TiN grains had an average size of $1.4 \mu \mathrm{m}$. These grains were uniformly distributed in the silicon nitride matrix. The microstructure of the matrix was similar to that of polycrystalline silicon nitride. 


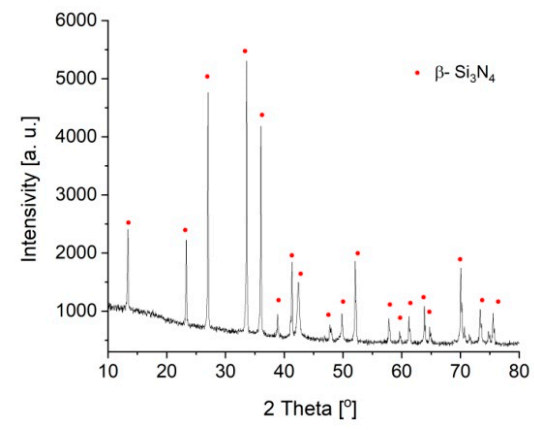

(a)

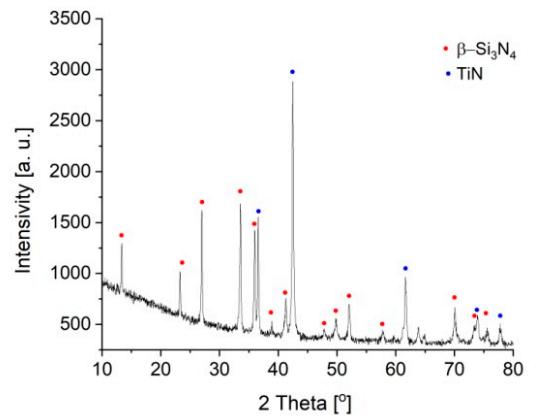

(b)

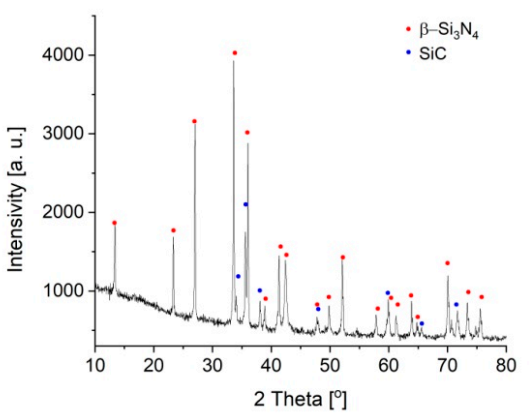

(c)

Figure 2. XRD patterns: (a) $\mathrm{Si}_{3} \mathrm{~N}_{4}$, (b) $\mathrm{Si}_{3} \mathrm{~N}_{4}+20 \mathrm{vol} \% \mathrm{SiC}$, and (c) $\mathrm{Si}_{3} \mathrm{~N}_{4}+20 \mathrm{vol} \% \mathrm{TiN}$.

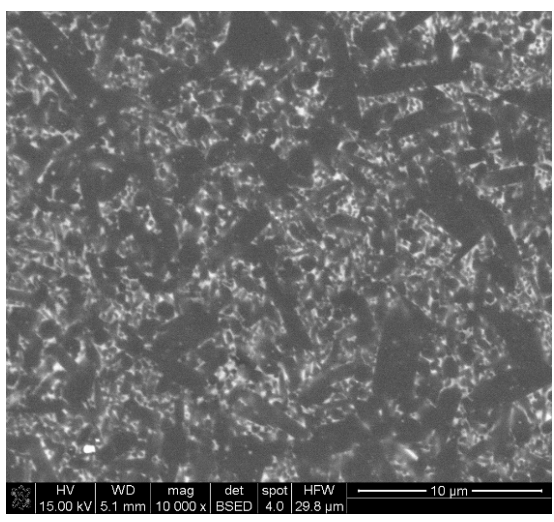

(a)

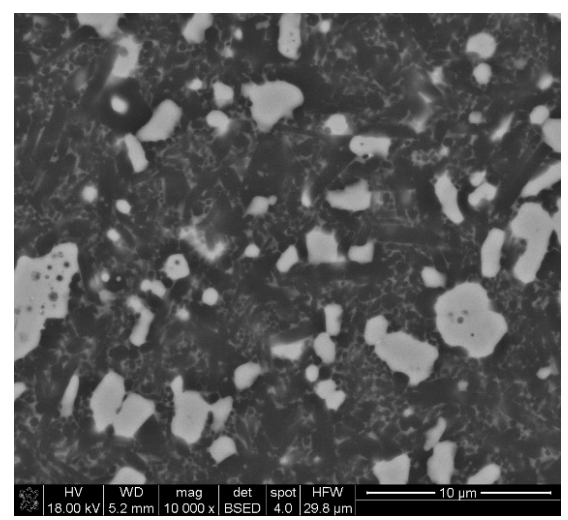

(b)

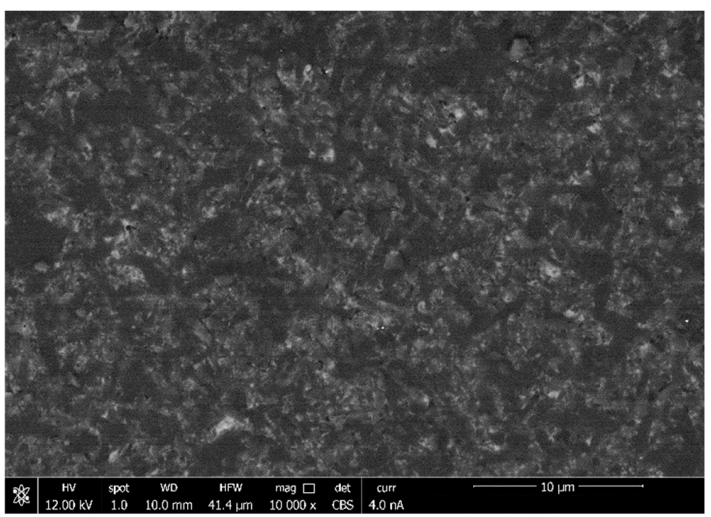

(c)

Figure 3. SEM observation of materials: (a) polycrystalline $\mathrm{Si}_{3} \mathrm{~N}_{4}$, (b) $\mathrm{Si}_{3} \mathrm{~N}_{4}+20 \% \mathrm{TiN}$, and (c) $\mathrm{Si}_{3} \mathrm{~N}_{4}+20 \% \mathrm{SiC}$. 
In composites with $\mathrm{SiC}$, the contrast between grains observed using a backscattered electron detector (BSE) was much smaller than in the case of composites with titanium nitride due to the similar chemical composition of $\mathrm{SiC}$ and $\mathrm{Si}_{3} \mathrm{~N}_{4}$ and the small difference between the atomic mass of carbon and nitrogen. However, the lighter-grey grains visible in Figure $3 c$ were silicon carbide; they were uniformly distributed in the microstructure and their average grain size was also around $1.4 \mu \mathrm{m}$. The microstructure of the silicon nitride matrix was also very similar to the reference sample.

The Young's modulus of polycrystalline silicon nitride was almost $300 \mathrm{GPa}$, and it increased with the addition of secondary phases in both types of composites, exceeding $320 \mathrm{GPa}$ for the $\mathrm{Si}_{3} \mathrm{~N}_{4}+20 \%$ TiN composite. The hardness of the reference sample was $13.3 \mathrm{GPa}$. The titanium nitride additive did not cause a great increase in hardness; for the composite with 20\% TiN, it was $13.6 \mathrm{GPa}$. Much greater hardness was measured for composites with silicon carbide. The hardness of $\mathrm{Si}_{3} \mathrm{~N}_{4}+20 \% \mathrm{SiC}$ was 15.3 GPa.

The fracture toughness of the reference sample was high $\left(8.5 \mathrm{MPa} \cdot \mathrm{m}^{0.5}\right)$. In $\mathrm{Si}_{3} \mathrm{~N}_{4}-\mathrm{TiN}$ systems, we observed a slight increase of fracture toughness as the amount of titanium nitride increased (Figure 4). The strength of these composites also increased with higher amounts of titanium nitride (Figure 4). In $\mathrm{Si}_{3} \mathrm{~N}_{4}-\mathrm{SiC}$ composites, the fracture toughness strongly decreased as the amount of $\mathrm{SiC}$ increased, while the strength increased, and for all composites, it exceeded $880 \mathrm{MPa}$ (Figure 4).

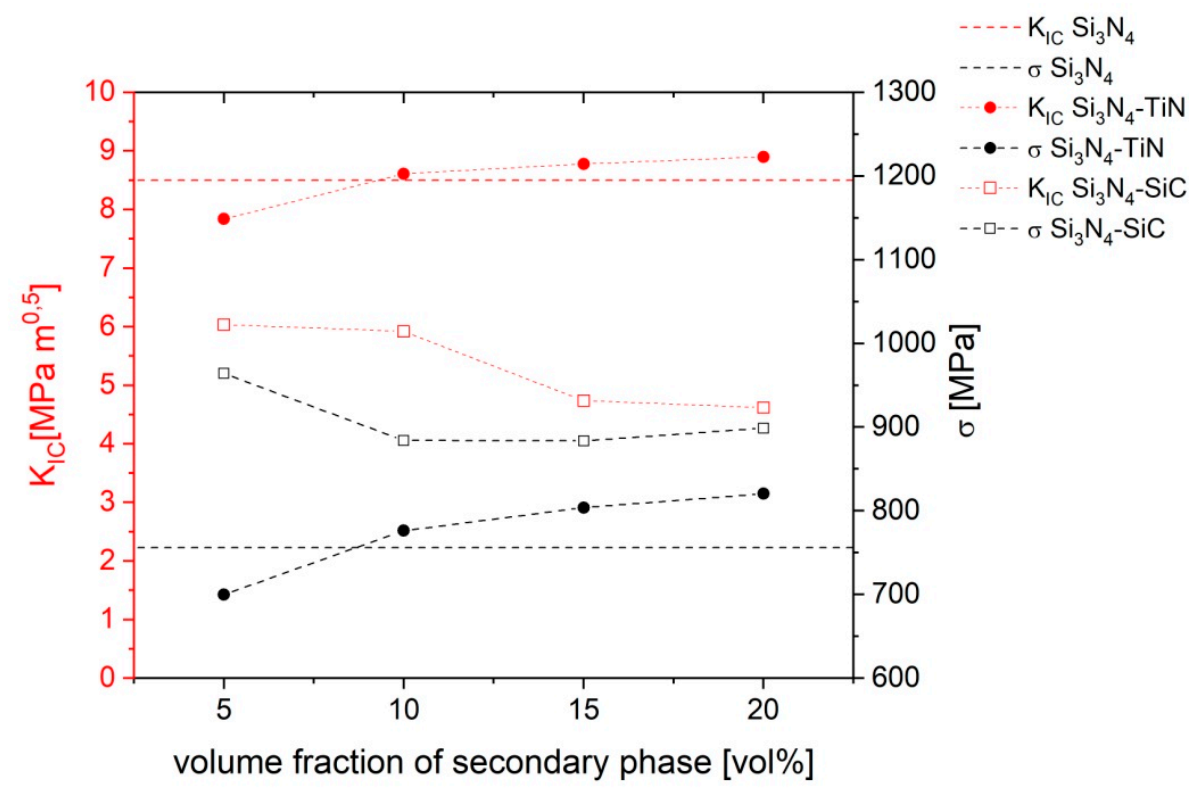

Figure 4. Fracture and strength of materials.

\subsection{Geometric 3D Models of Microstructure}

Models of polycrystalline silicon nitride and the composite are presented in Figure 5a,b, respectively.

The amount of elongated silicon nitride grains in the prepared model of polycrystalline $\mathrm{Si}_{3} \mathrm{~N}_{4}$ was $40 \%$. It would have been possible to increase the volume fraction of these grains by reducing the size of the grains below $0.8 \mu \mathrm{m}$, but this would have led to a significant increase in the numerous mesh elements required for model discretization. Moreover, grains with a length below $0.8 \mu \mathrm{m}$ have a width below $0.2 \mu \mathrm{m}$, so small grains are on the resolution level of SEM. In the works of Wippler [17,33], a greater number of elongated grains were created, but the author assumed that the grains can overlap and deform. The SEM observations of our research did not reveal deformed or overlapping grains, and because of that, these mechanisms were not allowed in the generation of our model. Elongated grains of silicon nitride were covered by the grain boundary amorphous phase. The volume fraction of this oxide phase in the model was $9.5 \%$, which is in good agreement with the experiment, where this 
volume fraction was around $8 \%$ (10 wt \% of sintering additives). The rest of the space in the model of polycrystalline silicon nitride was fulfilled by the isotropic $\mathrm{Si}_{3} \mathrm{~N}_{4}$, representing very small silicon nitride grains visible in the microstructure.

Models of composite materials (Figure 5b) contained an additional 20\% of the secondary phase. This caused a decrease in the amount of elongated grains to $21 \%$ and, hence, a decrease in the amount of the grain boundary phase to $5 \%$.
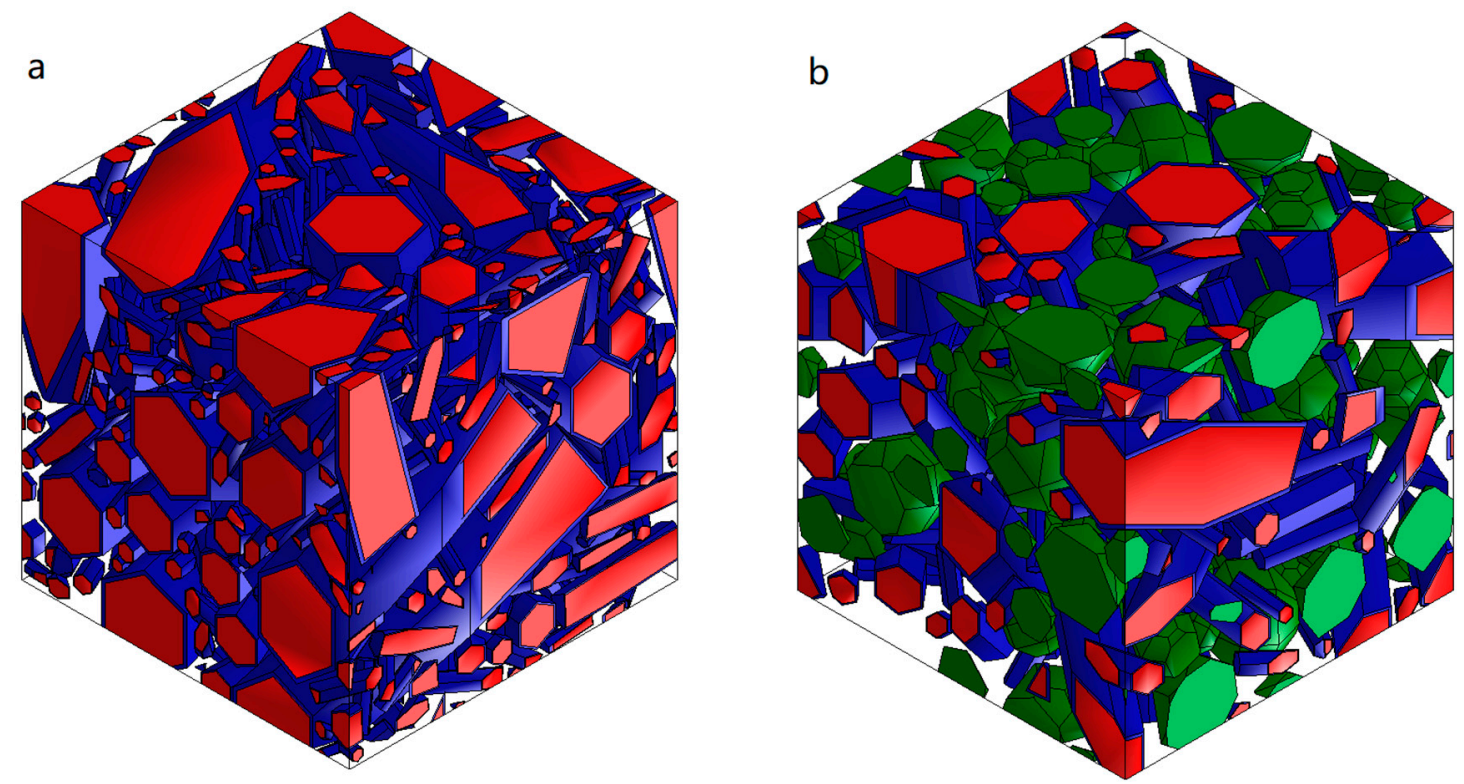

Figure 5. 3D microstructure of (a) polycrystalline silicon nitride and (b) silicon nitride-based composite materials with $20 \mathrm{vol} \%$ of secondary phase; red colour- silicon nitride grains, green colour- secondary phase grains, navy blue color- amorphous oxide phase.

\subsection{Residual Stresses Determined Using FEM}

Based on the average stresses determined using FEM, grains of $\mathrm{Si}_{3} \mathrm{~N}_{4}$ in polycrystalline silicon nitride were under slight compression (approx. -30 MPa), while tensile stresses (approx. $270 \mathrm{MPa}$ ) were present in the grain boundary phase (Table 5). This behavior corresponds with the results achieved analytically by Peterson and Tien [16]. However, the values of the stresses simulated in this study were lower than those in the abovementioned article [16].

Table 5. Average residual stresses in silicon nitride-based materials: finite element method (FEM) simulation.

\begin{tabular}{cccc}
\hline Material & $\begin{array}{c}\mathbf{S i}_{3} \mathbf{N}_{4} \\
{[\mathbf{M P a}]}\end{array}$ & $\begin{array}{c}\text { Grain Boundary Phase } \\
{[\mathbf{M P a}]}\end{array}$ & $\begin{array}{c}\text { Secondary Phase } \\
{[\mathbf{M P a}]}\end{array}$ \\
\hline $\mathrm{Si}_{3} \mathrm{~N}_{4}$ & -26.6 & 271.0 & - \\
$\mathrm{Si}_{3} \mathrm{~N}_{4}+20 \% \mathrm{SiC}$ & -69.9 & 257.2 & 204.1 \\
$\mathrm{Si}_{3} \mathrm{~N}_{4}+20 \% \mathrm{TiN}$ & -439.1 & 70.8 & 1654.6 \\
\hline
\end{tabular}

According to the histogram of stresses in polycrystalline silicon nitride (Figure 6a), we can assume that, even though the values of the average stresses in the grains were around $-30 \mathrm{MPa}$, these stresses were locally lower than -200 MPa. In the distribution of compressive stresses shown in Figure $7 \mathrm{~b}$, we can see that these minimum stress values (most compressive stresses) were located on some edges of elongated grains. Maximum tensile stresses were observed in the grain boundary phase (Figure 7a), and according to the histogram shown in Figure 6a, these stresses may locally exceed $400 \mathrm{MPa}$. 


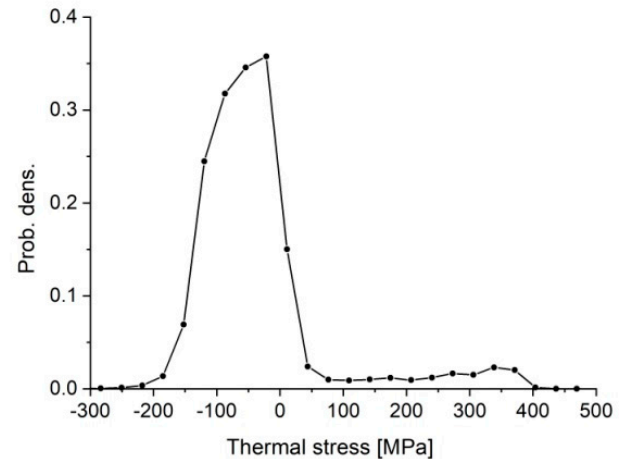

(a)

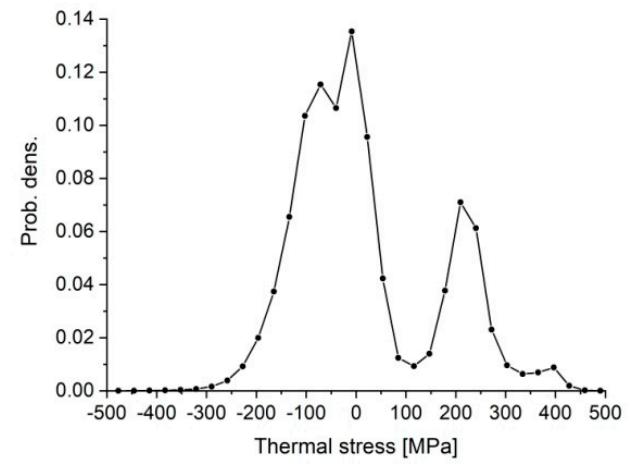

(b)

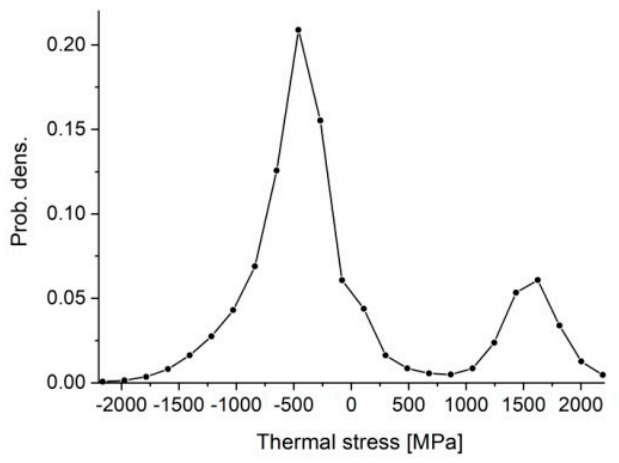

(c)

Figure 6. Histograms of residual stresses determined by FEM simulation for (a) $\mathrm{Si}_{3} \mathrm{~N}_{4}$, (b) $\mathrm{Si}_{3} \mathrm{~N}_{4}+\mathrm{SiC}$, and (c) $\mathrm{Si}_{3} \mathrm{~N}_{4}+\mathrm{TiN}$.

In $\mathrm{Si}_{3} \mathrm{~N}_{4}-\mathrm{SiC}$ composites, the average value of tensile stresses in the amorphous phase was very similar to the reference sample (Table 6). The simulation indicated that the incorporation of silicon carbide caused an increase in average compressive stresses in silicon nitride grains. Even though the average stresses were about $-70 \mathrm{MPa}$, they locally exceeded $-300 \mathrm{MPa}$ (Figure $6 \mathrm{~b}$ ). The secondary phase was under tensile stresses with an average value of $200 \mathrm{MPa}$. According to the distribution of stresses, the highest tension (Figure 7c) was localized in the grain boundary phase, while the highest compression (Figure 7d) can be observed locally in $\mathrm{Si}_{3} \mathrm{~N}_{4}$ between $\mathrm{SiC}$ grains.

The highest values of stresses were observed in $\mathrm{Si}_{3} \mathrm{~N}_{4}-\mathrm{TiN}$ composites. The calculated average compression in silicon nitride was $-400 \mathrm{MPa}$, and locally, as shown by the histogram in Figure $6 \mathrm{c}$, these stresses reached $-2000 \mathrm{MPa}$. Average tensile stresses in the grain boundary phase were reduced to $70.8 \mathrm{MPa}$. Titanium nitride grains were under strong tension; the calculated average stresses were around $1650 \mathrm{MPa}$, but according to the histogram, they locally exceeded $2000 \mathrm{MPa}$. The highest stresses were created on the contact of titanium nitride grains (Figure 7e). The lowest stresses were located in silicon nitride between titanium nitride grains (Figure 7f). 


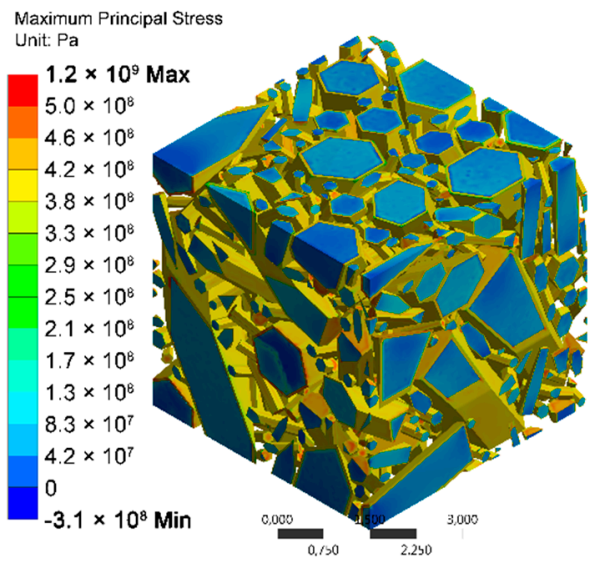

(a)

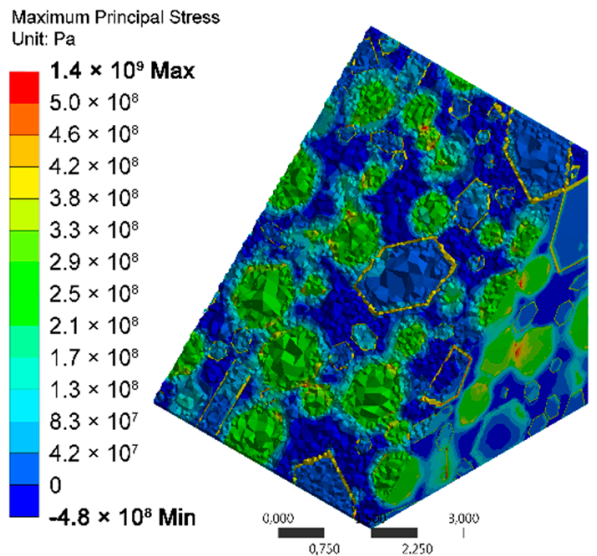

(c)

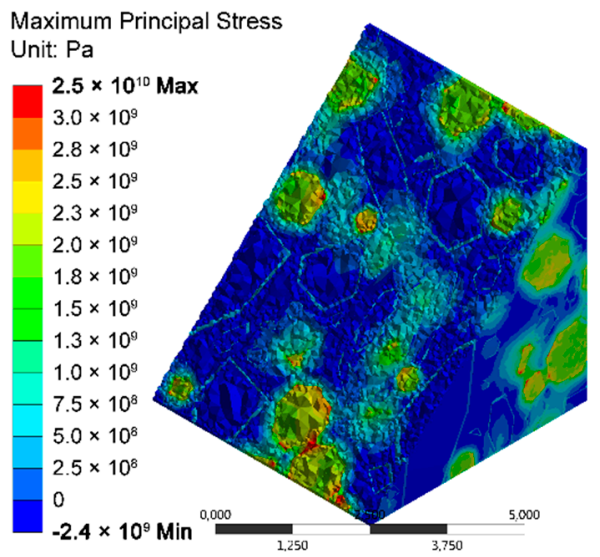

(e)

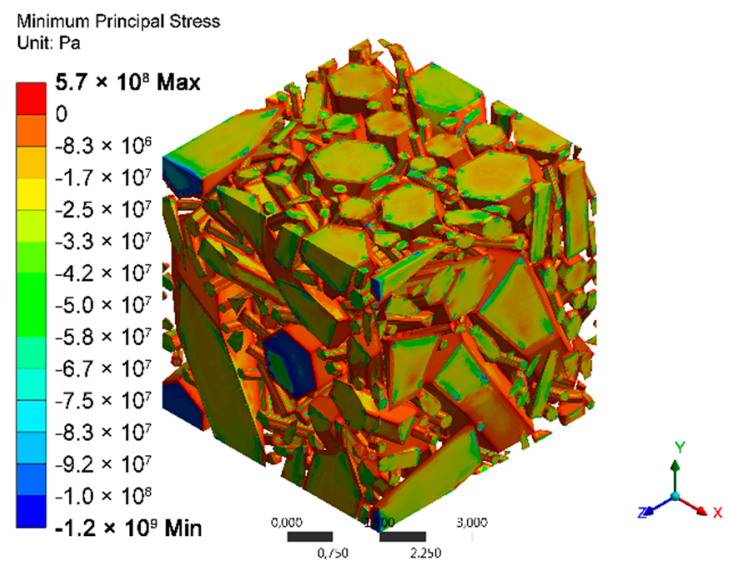

(b)

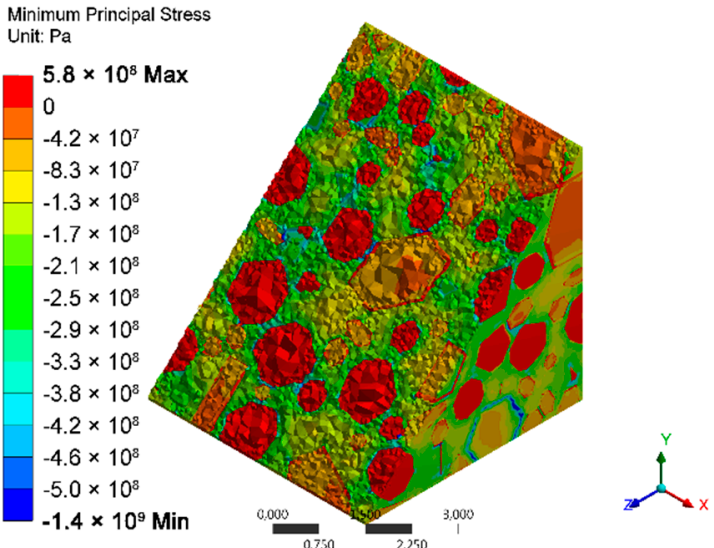

(d)

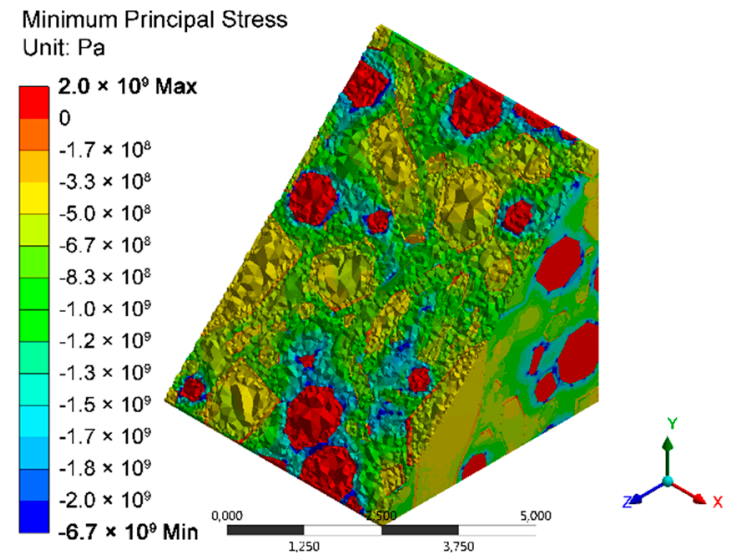

(f)

Figure 7. Distribution of residual thermal stresses: (a) maximum principal stresses in $\mathrm{Si}_{3} \mathrm{~N}_{4}$, (b) minimum principal stresses in $\mathrm{Si}_{3} \mathrm{~N}_{4}$, (c) maximum principal stresses in $\mathrm{Si}_{3} \mathrm{~N}_{4}+20 \% \mathrm{SiC}$, (d) minimum principal stresses in $\mathrm{Si}_{3} \mathrm{~N}_{4}+20 \% \mathrm{SiC}$, (e) maximum principal stresses in $\mathrm{Si}_{3} \mathrm{~N}_{4}+20 \% \mathrm{TiN}$, and (f) minimum principal stresses in $\mathrm{Si}_{3} \mathrm{~N}_{4}+20 \% \mathrm{TiN}$. Color scales and stress ranges for subsequent images are different.

\subsection{Measurement of Stresses Using the $\operatorname{Sin}^{2} \psi$ Method}

Measurements were made for polycrystalline silicon nitride and composites with $20 \%$ titanium nitride or silicon carbide with $6 \mathrm{wt} \%$ aluminum oxide and $4 \mathrm{wt} \%$ yttrium oxide. The results for $\mathrm{Si}_{3} \mathrm{~N}_{4}$ and the secondary phases in the analyzed composites are presented in Table 6 . The applied 
methodology enabled measurement of macrostresses for the depth of penetration of the surface layer in the range of $-70 \mu \mathrm{m}$ in the case of symmetrical Bragg-Brentano diffraction and 35-45 $\mu \mathrm{m}$ for the applied $\sin ^{2} \psi$ method.

The residual stresses determined for different samples varied considerably (Table 6 and Figure 8). In polycrystalline silicon nitride, the value of normal stresses was about $-160 \mathrm{MPa}$. In $\mathrm{Si}_{3} \mathrm{~N}_{4}-\mathrm{SiC}$ composites, normal compressive stresses in silicon nitride grains were higher than in the reference sample $(\sigma=-330 \mathrm{MPa})$, and in $\mathrm{SiC}$ grains, tensile stresses of about $200 \mathrm{MPa}$ were measured. These results are in agreement with the stresses simulated for bulk materials. Higher values of stresses were measured for composite materials, compressive stresses were determined for $\mathrm{Si}_{3} \mathrm{~N}_{4}$ grains, and tensile stresses were measured for silicon carbide. For these materials, values measured on the surface were higher than the values obtained by simulation for the bulk of the materials. This increase may have been caused by additional stresses introduced by material cutting and polishing. Lower values obtained in FEA simulations could also result from the assumptions made in the model: I) linear-elastic material properties, II) average values of thermal expansion coefficients in the considered temperature range. Despite the samples being relaxed, some stresses may have been induced. In $\mathrm{Si}_{3} \mathrm{~N}_{4}-\mathrm{TiN}$ composites, only compressive stresses were measured by XRD. In comparison with stresses determined for the bulk of this composite, the values were much lower, and in the case of titanium nitride grains, tensile stresses were calculated, while compressive stresses were measured using XRD. Probably during cutting, when additional stresses were induced, the yield limit of the material was locally suppressed, which caused cracking of the overloaded zones. After such cracking, stresses were released and only some compression was measured on the surface. This effect was observed only in $\mathrm{Si}_{3} \mathrm{~N}_{4}-\mathrm{TiN}$ composites, in which thermal residual stresses were extremely high due to the great difference in the thermal expansion coefficients.

Table 6. Measured surface residual stresses in silicon nitride-based materials and secondary phases. Diffraction constant $1 / 2 \mathrm{~S} 2\left(\mathrm{MPa}^{-1}\right)$ for particular phase $4.2 \times 10^{-6}$ for $\mathrm{Si}_{3} \mathrm{~N}_{4}, 2.4 \times 10^{-6}$ for $\mathrm{SiC}$, and $2.8 \times 10^{-6}$ for TiN.

\begin{tabular}{ccccc}
\hline \multirow{2}{*}{ Material } & \multicolumn{2}{c}{ Base Material $\mathbf{S i}_{\mathbf{3}} \mathbf{N}_{\mathbf{4}}$} & \multicolumn{2}{c}{ Secondary Phase } \\
\cline { 2 - 5 } & $\begin{array}{c}\text { Normal Stress } \boldsymbol{\sigma} \\
\mathbf{( M P a})\end{array}$ & $\begin{array}{c}\text { Shear Stress } \boldsymbol{\tau} \\
\mathbf{( M P a )}\end{array}$ & $\begin{array}{c}\text { Normal Stress } \boldsymbol{\sigma} \\
\mathbf{( M P a )}\end{array}$ & $\begin{array}{c}\text { Shear Stress } \boldsymbol{\tau} \\
\mathbf{( M P a )}\end{array}$ \\
\hline $\mathrm{Si}_{3} \mathrm{~N}_{4}$ & $-163 \pm 11$ & $55 \pm 10$ & - & - \\
$\mathrm{Si}_{3} \mathrm{~N}_{4}+20 \% \mathrm{SiC}$ & $-331 \pm 35$ & $89 \pm 8$ & $254 \pm 25$ & $-120 \pm 10$ \\
$\mathrm{Si}_{3} \mathrm{~N}_{4}+20 \% \mathrm{TiN}$ & $-195 \pm 12$ & $70 \pm 5$ & $-171 \pm 30$ & $-97 \pm 14$ \\
\hline
\end{tabular}

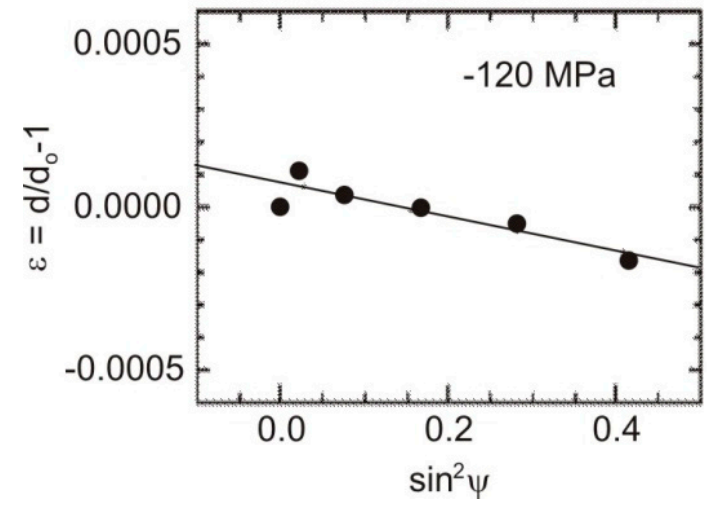

(a)

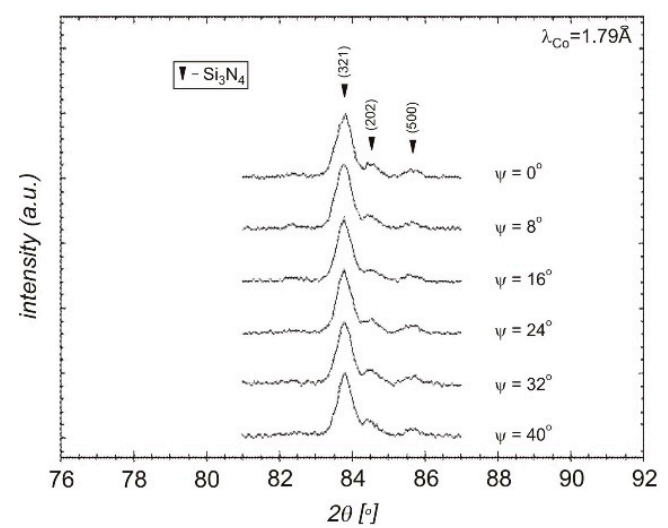

(b)

Figure 8. Linear relationship $\varepsilon_{\varphi \psi}=\mathrm{f}\left(\sin ^{2} \psi\right)+\mathrm{b}$ in the classical $\sin ^{2} \psi$ method (a) and view of the registered line $\{321\}$ for individual inclination angle $\psi(\mathbf{b})$. 


\subsection{The Influence of Stresses on Mechanical Properties}

The stress system in polycrystalline silicon nitride had a positive influence on the mechanical properties. The increase of fracture toughness of composites is caused by compressive stresses in grains and tensile stresses in the amorphous phase, which promotes cracking through the grain boundaries. Compressive stresses measured on the surface contribute to the strength of the materials. In composites with titanium nitride, the compressive stresses in the matrix were extremely high, which can cause annihilation of crack propagation, and owing to that, an increase of fracture. High values of stresses may also create some microcracks in the material, which beneficially influence fracture toughness. Surface stresses in this composite were also advantageous, and only compressive stresses were observed on the surface. In composites with silicon carbide, there were high compressive stresses in the silicon nitride grains and tensile stresses in the silicon carbide grains. This system of stresses caused a decrease of fracture. Probably, cracks went through tensile stress in silicon carbide grains, and low value of compression in silicon nitride was the reason of some intergranular cracking. Beneficial stress systems on the surface of these composites, and high values of compressive stresses may relax external tension, and thanks to that, cause the increase of strength.

\section{Conclusions}

1. Simplification during preparation of the 3D geometric models, regarding replacement of the smallest $\mathrm{Si}_{3} \mathrm{~N}_{4}$ grains by a continuous and isotropic constituent, allowed for effective calculations using the finite element method, without an excessive increase in the complexity of the calculation model (mesh density).

2. The results of the FEA simulation indicate a complex system of stress in materials based on $\mathrm{Si}_{3} \mathrm{~N}_{4}$. The silicon nitride phase is under compressive stress and the grains of secondary phases are under tensile stress. Very high stress values for $\mathrm{Si}_{3} \mathrm{~N}_{4}-\mathrm{TiN}$ indicate the possibility of microcracks in the material, which occur mostly on the surface and cause an increase of fracture toughness.

3. The results of XRD measurements of surface stresses confirmed the presence of compressive stress in silicon nitride grains. In the Si3N4-SiC composites, the values coincided with those obtained numerically for the solid material. In Si3N4-TiN composites, lower stress values confirmed relaxation through cracking.

4. The results of mechanical testing and stress analysis show that the high fracture toughness and strength of polycrystalline silicon nitride may be the effect of the advantageous stress system in this material. Compressive stress in grains and tensile stress in grain boundaries result in cracking through grain boundaries. Moreover, compressive stress on the surface are beneficial for the increase of the strength of materials. The investigation of Si3N4-TiN composites indicates that the system of stresses obtained by the distribution of the secondary phase with a much higher thermal expansion coefficient than the matrix has a beneficial influence on the fracture of materials. In composites with a small difference of thermal expansion coefficients between phases, the stresses were smaller and a decrease of fracture toughness was observed. On the other hand, in this kind of composite, we observed an increase of strength.

Author Contributions: Conceptualization, A.D.; methodology, A.D., G.G., and M.G.; software, G.G.; validation, A.D. and G.G.; formal analysis, A.D., G.G., and M.G.; investigation, A.D., G.G., and M.G.; resources, A.D.; data curation, G.G.; writing—original draft preparation, A.D.; writing—review and editing, G.G., M.G., and S.S.; visualization, A.D., G.G., and M.G.; supervision, A.D. and G.G.; project administration, A.D; funding acquisition, A.D. All authors have read and agreed to the published version of the manuscript.

Funding: This research was funded by the National Science Center, Poland, grant number UMO2016/21/N/ ST8/00185: "The influence of thermal stresses on mechanical properties of silicon nitride based particulate composites". The APC was funded by the National Science Center, Poland.

Acknowledgments: This research was supported in part by PL-Grid Infrastructure. 
Conflicts of Interest: The authors declare no conflicts of interest. The funders had no role in the design of the study; in the collection, analyses, or interpretation of data; in the writing of the manuscript; or in the decision to publish the results.

\section{References}

1. Katz, R.N. Applications of silicon nitreide based ceramics. Ind. Ceram. 1997, 17, 158-164.

2. Riley, F.L. Silicon Nitride and Related Materials. J. Am. Ceram. Soc. 2004, 83, 245-265. [CrossRef]

3. Huang, J.; Lee, M.-T.; Lu, H.; Lii, D. Microstructure, fracture behavior and mechanical properties of TiN/Si3N 4 composites. Mater. Chem. Phys. 1996, 45, 203-209. [CrossRef]

4. Gao, L.; Li, J.; Kusunose, T.; Niihara, K. Preparation and properties of TiN-Si3N4 composites. J. Eur. Ceram. Soc. 2004, 24, 381-386. [CrossRef]

5. Blugan, G.; Hadad, M.; Janczak-Rusch, J.; Kuebler, J.; Graule, T. Fractography, Mechanical Properties, and Microstructure of Commercial Silicon Nitride-Titanium Nitride Composites. J. Am. Ceram. Soc. 2005, 88, 926-933. [CrossRef]

6. Lojanová, S.; Tatarko, P.; Chlup, Z.; Hnatko, M.; Dusza, J.; Lenčéš, Z.; Šajgalík, P. Rare-earth element doped Si3N4/SiC micro/nano-composites—RT and HT mechanical properties. J. Eur. Ceram. Soc. 2010, 30, 1931-1944. [CrossRef]

7. Hegedûsová, L.; Kašiarová, M.; Dusza, J.; Hnatko, M.; Šajgalík, P. Mechanical properties of carbon-derived Si3N4+SiC micro/nano-composite. Int. J. Refract. Met. Hard Mater. 2009, 27, 438-442. [CrossRef]

8. Tomar, V. Analyses of the role of grain boundaries in mesoscale dynamic fracture resistance of $\mathrm{SiC}-\mathrm{Si} 3 \mathrm{~N} 4$ intergranular nanocomposites. Eng. Fract. Mech. 2008, 75, 4501-4512. [CrossRef]

9. Koch, H.; Gazza, G.E. On the $\alpha$ to $\beta$ phase transformation and grain growth during hot-pressing of Si3N4 containing MgO. Ceram. Int. 1980, 6, 51-56.

10. Hampshire, S. Silicon nitride ceramics-Review of structure, processing and properties. J. Achiev. Mater. Manuf. Eng. 2007, 24, 43-50.

11. Satet, R.L.; Hoffmann, M.J. Grain growth anisotropy of B-silicon nitride in rare-earth doped oxynitride glasses. J. Eur. Ceram. Soc. 2004, 24, 3437-3445. [CrossRef]

12. Tatarko, P.; Kašiarová, M.; Chlup, Z.; Dusza, J.; Šajgalík, P.; Vávra, I. Influence of rare-earth oxide additives and $\mathrm{SiC}$ nanoparticles on the wear behaviour of Si3N4-based composites at temperatures up to $900^{\circ} \mathrm{C}$. Wear 2013, 300, 155-162. [CrossRef]

13. Satet, R.L.; Hoffmann, M.J.; Cannon, R.M. Experimental evidence of the impact of rare-earth elements on particle growth and mechanical behaviour of silicon nitride. Mater. Sci. Eng. A 2006, 422, 66-76. [CrossRef]

14. Othmani, Y.; Böhlke, T.; Lube, T.; Fellmeth, A.; Chlup, Z.; Colonna, F.; Hashibon, A. Analysis of the effective thermoelastic properties and stress fields in silicon nitride based on EBSD data. J. Eur. Ceram. Soc. 2016, 36, 1109-1125. [CrossRef]

15. Residual Stress in Ceramics and Ceramic Composites. Available online: https://inis.iaea.org/collection/ NCLCollectionStore/_Public/24/022/24022074.pdf (accessed on 27 December 2019).

16. Peterson, I.M.; Tien, T. Effect of the Grain Boundary Thermal Expansion Coefficient on the Fracture Toughness in Silicon Nitride. J. Am. Ceram. Soc. 1995, 78, 2345-2352. [CrossRef]

17. Wippler, J.; Böhlke, T. Structure and fracture property relation for silicon nitride on the microscale. Comput. Mater. Sci. 2012, 64, 234-238. [CrossRef]

18. Bao, Y.; Liu, C.; Huang, J. Effects of residual stresses on strength and toughness of particle-reinforced TiN/Si3N4 composite: Theoretical investigation and FEM simulation. Mater. Sci. Eng. A 2006, 434, 250-258. [CrossRef]

19. Vogelgesang, R.; Grimsditch, M.; Wallace, J.S. The elastic constants of single crystal B-Si3N4. Appl. Phys. Lett. 2000, 76, 982-984. [CrossRef]

20. Henderson, C.M.B.; Taylor, D. Themal expansion of the nitride and oxide of silicon $\mathrm{n}$ relation to their structures. Trans. J. Br. Ceram. Soc. 1975, 74, 49-53.

21. Li, Z.; Bradt, R.C. The single crystal elastic constants of hexagonal SiC to 1000 C. Int. J. High Technol. Ceram. 1988, 4, 1-10. [CrossRef]

22. Li, Z.; Bradt, R.C. Thermal expansion of the hexagonal $(6 \mathrm{H})$ polytype of silicon carbide. J. Am. Ceram. Soc. 1986, 66, 863-866. [CrossRef] 
23. Kim, J.O.; Achenbach, J.D.; Mirkarimi, P.B.; Shinn, M.; Barnett, S.A. Elastic constants of single-crystal transition-metal nitride films measured by line-focus acoustic microscopy. J. Appl. Phys. 1992, 72, $1805-1811$. [CrossRef]

24. Pierson, H.O. Handbook of Refractory Carbides and Nitrides: Properties, Characteristics, Processing, and Applications; Noyes Publication: Westwood, NJ, USA, 1996; p. 362.

25. Hill, R. The elastic behaviour of a crystalline aggregate. Proc. Phys. Soc. Sect. A 1952, 65. [CrossRef]

26. Hampshire, S.; Nestor, E.; Flynn, R.; Besson, J.-L.; Rouxel, T.; Lemercier, H. Yttrium oxynitride glasses: Properties and potential for crystallisation to glass-ceramics. J. Eur. Ceram. Soc. 1994, 14, 261-273. [CrossRef]

27. Suquet, P. Elements of homogenization for inelastic solid mechanic. Lect. Notes Phys. 1985, 272, 194-275.

28. Xia, Z.; Zhang, Y.; Ellyin, F. A unified periodical boundary conditions for representative volume elements of composites and applications. Int. J. Solids Struct. 2003, 40, 1907-1921. [CrossRef]

29. Grabowski, G. Modelling of thermal expansion of single- and two-phase ceramic polycrystals utilising synthetic 3D microstructures. Comput. Mater. Sci. 2019, 156, 7-16. [CrossRef]

30. Skryzpek, S.J. New Approach to Residual Macro-Stresses Measurement Due to Grazing Angle X-ray Diffraction Geometry; Uczelniane Wyd. Nauk.-Dydaktyczne AGH: Krakow, Poland, 2002; ISSN 0867-6631.

31. Ratuszek, W.; Kusior, E.; Skrzypek, S.J.; Baczman, A. New approach to stress analysis based on grazing-incidence X-ray diffraction. Appl. Crystallogr. 2001, 34, 427-435.

32. Cullity, B.D.; Stock, S.R. Elements of X-ray Diffraction, 3rd ed.; Pearson India: New York, NY, USA, 2010; ISBN 109789332535169.

33. Wippler, J.; Böhlke, T. An algorithm for the generation of silicon nitride structures. J. Eur. Ceram. Soc. 2012, 32, 589-602. [CrossRef]

(C) 2020 by the authors. Licensee MDPI, Basel, Switzerland. This article is an open access article distributed under the terms and conditions of the Creative Commons Attribution (CC BY) license (http://creativecommons.org/licenses/by/4.0/). 